\title{
Effects of the Sports on the Personality Traits and the Domains of Creativity
}

\author{
Elif Top ${ }^{1} \&$ Mustafa Akil ${ }^{1, *}$ \\ ${ }^{1}$ Faculty of Sports Sciences, University of Uşak, Uşak, Turkey \\ *Correspondence: Faculty of Sports Sciences, University of Uşak, Uşak, Turkey. Tel: 90-276-221-2221. E-mail: \\ mustafa.akil@usak.edu.tr
}

Received: April 17, 2018

Accepted: May 5, 2018 Online Published: May 27, 2018

doi:10.5430/wje.v8n3p56

URL: https://doi.org/10.5430/wje.v8n3p56

\begin{abstract}
The present study investigated the correlation between the personality traits of the university students who were engaged in sports and the ones who were not engaged in sports, and their domains of creativity. A total number of 593 students studying in the faculty of sports sciences and in other departments were included the study. As the data collection tools, "Revised/Shortened Form Eysenck Personality Questionnaire (EPQ-RS)" and "Kaufman Domains of Creativity Scale" (K-DOCS) were used in the present study. When the creativity and personality traits of the female and male students were compared, it was found out that the neuroticism points of female students were found to be higher comparing to the male students. While the male students had higher points in in the domains of scholarly creativity, mechanical/scientific creativity, artistic and psychoticism, the female students were found to have scored higher points in the other domains. When the creativity and personality traits of the students who were engaged in sports and those of the students who were not engaged in sports were compared, the extroverted characteristics were found higher and psychoticism characteristics were lower of the individuals engaged in sports, while no difference was found in other domains. Consequently, it could be said that female students were more neurotic, that the individuals engaged in sports were more extroverted compared to the ones not engaged in sports, and that male students have higher points compared to the female students in the domains of scholarly, mechanical/scientific, artistic and psychoticism.
\end{abstract}

Keywords: sports, personality, creativity

\section{Introduction}

Human beings tend to assess their abilities immediately in the face of the events they encounter in their daily lives (Ackerman \& Wolman, 2007; Freund \& Kasten, 2012). The question "Do I have the creativity required by this work?" is an example of this assessment (Hughes, Furnham, \& Batey, 2013). It shouldn't be forgotten that our effort to assess ourselves is related to what we try to do and how much effort we make (Deci \& Ryan, 2000; Haimovitz, Wormington, \& Corpus, 2011). Our efforts to determine our abilities are of importance not only in terms of our personality, but also in terms of our performance (Ackerman, Chamorro-Premuzic, \& Furnham, 2011; Putwain, Kearsley, \& Symes, 2012). Recent studies have focused on personal traits such as emotional intelligence (Petrides, Furnham, \& Martin, 2004), general human performance (Furnham, von Stumm, Makendrayogan, \& Chamorro-Premuzic, 2009), attention (Menglekamp \& Jager, 2007) and creativity (Putwain et al., 2012). Some of the previous studies have addressed the subject of how related are the personality factors to creativity, and suggested that the personality structures especially such as the extroversion (Batey, Furnham, \& Safiullina, 2010; Chamorro-Premuzic \& Reichenbacher, 2008; Furnham, Crump, Batey, \& Chamorro-Premuzic, 2009), being conscientious (Feist, 1998) and neuroticism (Chamorro-Premuzic \& Reichenbacher, 2008; Furnham et al., 2009) have a positive correlation with creativeness. However, such studies have generally been interested in the classical creativeness domains such as music, arts and literature (Batey \& Furnham, 2006; Runco, 2004). Yet, creative behavior plays an important part in sports performance as well. During a contest, an athlete can go in quest of original solution ideas. Creativity in sports means that the athlete has the ability to produce changeable, rare and flexible decisions during the contest (Memmert \& Roth, 2007). Different parts of the brain serve in the special and suddenly emerging events (Cabeza \& Nyberg, 2000; Duncan \& Owen, 2000), and some parts of the brain are 
responsible for the creative performance. However, it should be remembered that creativity is a multi-combinational process (Dietrich, 2004).

Today, the process of scouting talented athletes constitutes one of the most important issues in sports. Thus, knowing about the personality traits and creativity domains of athletes can be an opportunity for sports consultants, coaches and experts. Thus, the main objective of the present study is to investigate the personality traits and creativity domains of the athletes engaged in individual or team sports or the individuals who are not engaged in any sports branch, and to compare them with each other.

\section{Method}

\subsection{Sample}

The sample of the present study comprised 593 students studying in various departments of universities and participating in the study on a voluntary basis. Of these students, $185(31.20 \%)$ were female and $408(68.80 \%)$ male. In the present study, a questionnaire involving the demographical characteristics was used to determine the socio-demographical characteristics of the students, the Eysenck Personality Questionnaire the Revised/Short Form (EPQ-RS), which was developed by Francis, Brown, and Philipchalk (1992) and adapted to Turkish by Karanc1, Dirik and Yorulmaz (2007) was employed, and the "Kaufman Domains of Creativity Scale (K-DOCS)", which was developed by Kaufman (2012) and adapted to Turkish by Şahin (2016) was used to evaluate the domains of creativity. The demographical information about the participants is given in Table 1. The present study was approved by the Social and Human Sciences Scientific Research and Publications Ethics Council of Uşak University with the date and the number of 2018-35.

Table 1. Demographical Characteristics of the Participants

\begin{tabular}{|c|c|c|c|c|c|c|c|c|c|}
\hline & & \multicolumn{2}{|c|}{$\begin{array}{l}\text { Are you engaged } \\
\text { in sports? }\end{array}$} & \multicolumn{2}{|c|}{$\begin{array}{c}\text { Which branch of sports } \\
\text { do you perform? }\end{array}$} & \multicolumn{2}{|c|}{ Department } & \multirow[b]{2}{*}{ Average Age } & \multirow[b]{2}{*}{ Total } \\
\hline & & No & Yes & $\begin{array}{c}\text { Individual } \\
\text { Sports }\end{array}$ & Team Sports & $\begin{array}{c}\text { Sports } \\
\text { Sciences }\end{array}$ & Other & & \\
\hline \multirow{2}{*}{ Gender } & Female & 58 & 127 & 75 & 67 & 85 & 100 & $21.42 \pm 2.20$ & 185 \\
\hline & Male & 94 & 314 & 139 & 225 & 207 & 201 & $22.05 \pm 2.22$ & 408 \\
\hline
\end{tabular}

\subsection{Eysenck Personality Questionnaire the Revised/Short Form (EPQ-RS)}

Francis et al. (1992) developed the EPQ-RS by revising the Eysenck Personality Questionnaire (Eysenck \& Eysenck, 1975 ) and the short form of the same questionnaire (Eysenck, Eysenck \& Barrett, 1985). The questionnaire comprises 24 entries and it considers the personality in three main factors: extroversion, neuroticism and psychoticism. In addition, the sub-scale of lying is intended to prevent the bias during the application of the questionnaire and to control its validity. In this questionnaire where each factor is evaluated by means of 6 entries, the respondents are asked to answer each question in the Yes (1) - No (0) format. The point that can be scored for each personality trait varies between 0 and 6 . While extroversion represents sociability and impulsivity, the people who score high in this dimension are defined as people who like communicating with other people, who are outgoing, and who prefer being with people rather than being alone. In the factor analysis carried out, the 24 entries of the questionnaire were divided into four factors, namely the dimensions of neuroticism, extroversion, psychoticism and lie, which is in congruence with the original questionnaire. The internal consistency coefficient of the questionnaire was found to be $.78, .65, .42$ and .64 for the dimensions of extroversion, neuroticism, psychoticism and lying, respectively, and the test-retest consistency was found to be $.84, .82, .69$ and .69 for the same dimensions, respectively (Karanc1 et al., 2007). For the present study, the Cronbach $\alpha$ internal consistency coefficients of the measuring tool were examined, and the results were found to be appropriate. The results are given in Table 2 .

\subsection{Kaufman Domains of Creativity Scale (K-DOCS)}

Developed by Kaufman (2012), Kaufman Domains of Creativity Scale (K-DOCS) is a 50-entry scale based on the opinion that creativity comprises multiple domains. K-DOCS comprises five sub-factors, namely scholarly, scientific/mechanical, performance (encompassing writing and music), everyday/self and artistic. Two different scores can be obtained from K-DOCS, which are the score based on each sub-factor, and the general score for the 
scale that is the total of those scores. Scoring high is an indication that the level of creativity is high. It was prepared as a five-point (I am much more creative; I am more creative; I am neither more nor less creative; I am less creative; I am much less creative) Likert-type scale. Then the scale was adapted to Turkish by Şahin (2016). The adaptation produced a five-factor structure composed of 41 entries. By means of the Confirmatory Factor Analysis (CFA), the fit indices of the model were found to be as follows: $\chi^{2}(241)=1480.75, \mathrm{p}<.01 ; \chi^{2} / \mathrm{Sd}=1.93 \mathrm{RMSEA}=.06$, $\mathrm{SRMR}=.074, \mathrm{CFI}=.93$ and $\mathrm{GFI}=.78$. The internal consistency reliability coefficient of the K-DOCS was determined to be .87 for the factor of scholar creativity, .84 for the scientific/mechanical creativity, .86 for performance creativity, .77 for everyday/self creativity, and .83 for artistic creativity, while the total score for the scale was found out to be .90 . The Cronbach $\alpha$ internal consistency coefficients of the measuring tool were also examined for the present study, and the results were found to be appropriate. The results are given in Table 2.

Table 2. Descriptive Statistics and the Internal Consistency Coefficients of EPQ-RS and K-DOCS

\begin{tabular}{llccc}
\hline \multirow{2}{*}{ Measurement tools } & Sub-areas & \multicolumn{2}{c}{ Points } & \multirow{2}{*}{$\alpha$} \\
\cline { 3 - 4 } EPQ-RS & Neuroticism & 3.28 & 1.58 & .68 \\
& Extroversion & 3.91 & 1.52 & .69 \\
& Psychoticism & 2.02 & 1.23 & .72 \\
& Lie & - & - & - \\
\hline \multirow{3}{*}{ K-DOCS } & Scholarly & 32.69 & 7.96 & .73 \\
& Mechanical/Scientific & 18.65 & 6.31 & .75 \\
& Performance & 26.30 & 8.29 & .71 \\
& Self / Everyday & 31.06 & 8.00 & .79 \\
& Artistic & 14.07 & 4.90 & .69 \\
\hline
\end{tabular}

The Cronbach $\alpha$ internal consistency coefficient for the K-DOCS was found to be .88 in total, and to be in the interval of $.73-.69$ for its sub-tests; and to be in the interval of $.72-.68$ for the sub-tests of the EPQ-RS.

\subsection{Data Analysis}

SPSS (Statistical Package for Social Sciences) for Windows v25 software was used for the analysis of the findings obtained. The t-test for independent samples was employed for the analysis of the data obtained in the study. Regression analysis was used in order to understand the explanatory capacity of the variables, and the pearson correlation analysis was employed in order to determine the correlations between the scales. The results were considered at the reliability level of $95 \%$, and the significance was considered to be at the level of $p<0.05$ on a two-way basis.

\section{Results}

Table 3. The Correlation between the Sub-Dimensions of K-DOCS and EPQ-RS

\begin{tabular}{lccc}
\hline & \multicolumn{3}{c}{ EPQ-RS } \\
\cline { 2 - 4 } K-DOCS & Neuroticism & Extroversion & Psychoticism \\
\hline Scholarly & .037 & -.021 & .045 \\
Mechanical/Scientific & .037 & -.035 & .043 \\
Performance & .003 & -.045 & .014 \\
Self / Everyday & -.043 & .005 & .056 \\
Artistic & -.073 & .005 & .034 \\
\hline
\end{tabular}

A positive but statistically insignificant correlation was determined between the personality traits and the creativity sub-domains $(\mathrm{p}>0.05)$. 
Table 4. Comparison of the Creativity and Personality Traits of the Female and Male Participants

\begin{tabular}{|c|c|c|c|c|c|c|c|}
\hline & Gender & $\mathrm{N}$ & $\overline{\mathrm{X}}$ & $\mathrm{Sd}$ & $\mathrm{t}$ & df & $\mathrm{p}$ \\
\hline \multirow{2}{*}{ Scholarly } & Female & 185 & 32,62 & 7.72 & -.129 & 591 & .897 \\
\hline & Male & 408 & 32.71 & 8.07 & & & \\
\hline \multirow{2}{*}{ Mechanical/Scientific } & Female & 185 & 18.34 & 6.47 & -.801 & 591 & .423 \\
\hline & Male & 408 & 18.71 & 6.23 & & & \\
\hline \multirow{2}{*}{ Performance } & Female & 185 & 26.45 & 7.78 & .301 & 591 & .764 \\
\hline & Male & 408 & 26.23 & 8.52 & & & \\
\hline \multirow{2}{*}{ Self / Everyday } & Female & 185 & 31.23 & 7.97 & .366 & 591 & .714 \\
\hline & Male & 408 & 30.97 & 8.01 & & & \\
\hline \multirow{2}{*}{ Artistic } & Female & 185 & 13.87 & 5.22 & -.659 & 591 & .510 \\
\hline & Male & 408 & 14.16 & 4.74 & & & \\
\hline \multirow{2}{*}{ Neuroticism } & Female & 185 & 3.50 & 1.54 & 2.262 & 591 & $.024 *$ \\
\hline & Male & 408 & 3.19 & 1.59 & & & \\
\hline \multirow{2}{*}{ Extroversion } & Female & 185 & 4.08 & 1.55 & 1.766 & 591 & .078 \\
\hline & Male & 408 & 3.84 & 1.50 & & & \\
\hline \multirow{2}{*}{ Psychoticism } & Female & 185 & 2.00 & 1.23 & -.248 & 591 & .804 \\
\hline & Male & 408 & 2.03 & 1.22 & & & \\
\hline
\end{tabular}

$$
* \mathrm{p}<0.05
$$

When the creativity and personality traits of the female and male participants were compared, the neuroticism scores of the female students were found to differ significantly from those of the male students $\left(\mathrm{t}_{0.05: 591}=2.262 ; \mathrm{p}<0.05\right)$. The comparisons carried out in the creativity domains revealed that the male students had scored higher in the domains of scholarly creativity, scientific/mechanical creativity, artistic creativity and psychoticism, while the female students had scored higher in other domains, although the differences were not statistically significant (Table 4).

Table 5. Comparison of the Creativity and Personality Traits of the Participants Who Are Engaged in Sports and Those Who Are Not

\begin{tabular}{lccccccc}
\hline & $\begin{array}{c}\text { Are you engaged in } \\
\text { sports? }\end{array}$ & $\mathrm{N}$ & $\overline{\mathrm{X}}$ & $\mathrm{Sd}$ & $\mathrm{t}$ & $\mathrm{df}$ & $\mathrm{p}$ \\
\hline \multirow{2}{*}{ Scholarly } & No & 152 & 32.72 & 8.10 & .061 & 591 & .951 \\
& Yes & 441 & 32.67 & 7.92 & & & \\
Mechanical/Scientific & No & 152 & 19.21 & 6.32 & 1.276 & 591 & .203 \\
& Yes & 441 & 18.46 & 6.29 & & & \\
Performance & No & 152 & 27.37 & 8.04 & 1.854 & 591 & .064 \\
& Yes & 441 & 25.93 & 8.35 & & & \\
Self / Everyday & No & 152 & 31.88 & 7.40 & 1.484 & 591 & .138 \\
\multirow{3}{*}{ Artistic } & Yes & 441 & 30.77 & 8.17 & & & \\
& No & 152 & 14.26 & 5.02 & .556 & 591 & .578 \\
Neuroticism & Yes & 441 & 14.00 & 4.85 & & & \\
\multirow{2}{*}{ Extroversion } & No & 152 & 3.23 & 1.78 & -.494 & 591 & .622 \\
\multirow{2}{*}{ Psychoticism } & Yes & 441 & 3.30 & 1.53 & & & \\
& No & 152 & 3.60 & 1.58 & -2.970 & 591 & $.003 *$ \\
\hline p & Yes & 441 & 4.02 & 1.48 & & & \\
& No & 152 & 2.18 & 1.09 & 1.937 & 591 & .053 \\
\hline
\end{tabular}

$* \mathrm{p}<0.05$

When the creativity and personality traits of the participants who were engaged in sports and those who were not were compared, the extroversion status of the ones engaged in sports was found to differ significantly $\left(\mathrm{t}_{0.05: 591}=-2.970\right.$; $\mathrm{p}<0.05$ ). No difference was found in other areas (Table 5). 
Table 6. Comparison of the Creativity and Personality Traits of the Participants Studying in the Faculty of Sports Sciences and Those of the Ones Studying in Other Departments

\begin{tabular}{|c|c|c|c|c|c|c|c|}
\hline & Department & $\mathrm{N}$ & $\overline{\mathrm{X}}$ & $\mathrm{Sd}$ & $\mathrm{t}$ & $\mathrm{df}$ & $\mathrm{p}$ \\
\hline \multirow{2}{*}{ Scholarly } & Other Faculties & 301 & 32.43 & 7.76 & -.780 & 591 & .436 \\
\hline & Faculty of Sports Sciences & 292 & 32.94 & 8.16 & & & \\
\hline \multirow{2}{*}{ Mechanical/Scientific } & Other Faculties & 301 & 19.12 & 6.21 & 1.853 & 591 & .064 \\
\hline & Faculty of Sports Sciences & 292 & 18.16 & 6.38 & & & \\
\hline \multirow{2}{*}{ Performance } & Other Faculties & 301 & 26.74 & 8.01 & 1.310 & 591 & .191 \\
\hline & Faculty of Sports Sciences & 292 & 25.84 & 8.56 & & & \\
\hline \multirow{2}{*}{ Self / Everyday } & Other Faculties & 301 & 31.33 & 7.77 & .845 & 591 & .399 \\
\hline & Faculty of Sports Sciences & 292 & 30.77 & 8.22 & & & \\
\hline \multirow{2}{*}{ Artistic } & Other Faculties & 301 & 14.23 & 4.77 & .841 & 591 & 401 \\
\hline & Faculty of Sports Sciences & 292 & 13.90 & 5.02 & & & \\
\hline \multirow{2}{*}{ Neuroticism } & Other Faculties & 301 & 3.27 & 1.59 & -.196 & 591 & .845 \\
\hline & Faculty of Sports Sciences & 292 & 3.30 & 1.57 & & & \\
\hline \multirow{2}{*}{ Extroversion } & Other Faculties & 301 & 3.67 & 1.51 & -3.973 & 591 & $.000^{*}$ \\
\hline & Faculty of Sports Sciences & 292 & 4.16 & 1.48 & & & \\
\hline \multirow{2}{*}{ Psychoticism } & Other Faculties & 301 & 2.12 & 1.17 & 2.044 & 591 & $.041 *$ \\
\hline & Faculty of Sports Sciences & 292 & 1.91 & 1.26 & & & \\
\hline
\end{tabular}
$*_{p}<0.05$

When the creativity and personality traits of the participants who were studying in the faculty of sports sciences and those of the ones studying in other departments were compared, the extroversion $\left(\mathrm{t}_{0.05: 591}=-3.973\right)$ and psychoticism $\left(\mathrm{t}_{0.05: 591}=2.044\right)$ status of the participants studying in the faculty of sports sciences were found to differ significantly (Table 6).

Table 7. Comparison of the Creativity and Personality Traits of the Participants Engaged in Individual Sports and Those of the Ones Engaged in Team Sports

\begin{tabular}{llcccccc}
\hline & Branch of Sports & $\mathrm{N}$ & $\overline{\mathrm{X}}$ & $\mathrm{Sd}$ & $\mathrm{t}$ & $\mathrm{df}$ & $\mathrm{p}$ \\
\hline \multirow{2}{*}{ Scholarly } & Individual Sports & 190 & 32.58 & 7.86 & -.111 & 409 & .912 \\
& Team Sports & 245 & 32.66 & 8.00 & & & \\
Mechanical/Scientific & Individual Sports & 190 & 18.46 & 6.04 & -.008 & 433 & .993 \\
& Team Sports & 245 & 18.35 & 6.49 & & & \\
Performance & Individual Sports & 190 & 26.17 & 8.52 & .418 & 433 & .676 \\
& Team Sports & 245 & 25.84 & 8.24 & & & \\
Self/ Everyday & Individual Sports & 190 & 30.54 & 8.49 & -.531 & 433 & .596 \\
Artistic & Team Sports & 245 & 30.96 & 7.98 & & & \\
& Individual Sports & 190 & 14.18 & 4.90 & .613 & 433 & .540 \\
Neuroticism & Team Sports & 245 & 13.90 & 4.81 & & & \\
\multirow{3}{*}{ Extroversion } & Individual Sports & 190 & 3.25 & 1.60 & -.606 & 433 & .545 \\
Psychoticism & Team Sports & 245 & 3.34 & 1.49 & & & \\
& Individual Sports & 190 & 4.03 & 1.53 & .220 & 433 & .826 \\
& Team Sports & 245 & 4.00 & 1.44 & & & \\
& Individual Sports & 190 & 1.99 & 1.26 & .427 & 404 & .670 \\
& Team Sports & 245 & 1.94 & 1.25 & & & \\
\hline
\end{tabular}

When the creativity and personality traits of the participants who were engaged in individual sports and those of the ones engaged in team sports were compared, no statistically significant difference was found (Table 7). 


\section{Discussion}

When the personality traits of the female and male students were compared, the neuroticism scores of the female students were found to be higher than those of the male students $(\mathrm{p}<0.05)$. Although the difference is not statistically significant, the psychoticism scores of the male participants are higher. The study conducted by Shevlin, Bailey, and Adamson (2002) found that the neuroticism scores of the female participants differed significantly from the scores of the male participants. Other previous studies (Hanin, Eysenck, Eysenck, \& Barrett, 1991; Maltby \& Talley, 1998; Forrest, Lewis, \& Shevlin, 2000) also found that male candidates had higher average scores in the psychoticism sub-test of the scale, while the female candidates had higher average scores in the neuroticism sub-test. Neuroticism is also characterized by the emotional instability, sensitivity and dependence (Lehmann, Denissen, Allemand \& Penke, 2013). In the present study, neuroticism has been found to be the only psychological variable differing between the male and female participants. Female participants score higher in neuroticism in studies in general (Lehmann et al., 2013; Lynn et al., 1997). Similar differences between the genders in terms of neuroticism have been observed for different age groups as well (Chapman, Duberstein, Sörensen, \& Lyness, 2007). Some authors suggested that the gender-related differences in personality are repeatable at an intercultural level as well (Vassend, Røysambi, \& Nielsen, 2013). This results from the fact that psychoticism is related to the male gender role and neuroticism is related to the female gender role (Shevlin et al., 2002). In the present study, a positive, small and insignificant correlation has been determined between the scores of personality traits and arts sub-domains between the K-DOCS and EPQ-RS (Table 3). A previous study has also found out significant correlations between the creative personality scale and self-efficacy, empathy, benefit and perception (Wolfradtz, Felfe, \& Köster, 2001). In another similar study, a significant and positive correlation was determined between the creative personality and the state of wellness, self-control, sociability and global emotional intelligence (Sanchez-Ruiz, Hernandez-Torrano, Perez-Gonzalez, Batey, \& Petrides, 2011). The fact that no difference has been found in the present study might have resulted from using different scales or the environmental conditions. There is a need for more in-depth and long-term studies on this subject. As for the creativity sub-dimension, the male students have been reported to score higher in the domains of scholarly creativity, scientific/mechanical creativity and artistic creativity although the differences are statistically significant ( $>0.05$ ), while the female students have been reported to score higher in other domains. The variable of gender has been investigated in the context of creativity primarily by means of the studies using general creativity tests. In the study they conducted on the creativity and the gender-related differences, Baer and Kaufman (2008) reviewed the findings of various studies and stated that significant differences had not been found in most of those studies, and that females had scored higher in the sub-tests of some studies, while males had scored higher in the sub-tests of the others. Similar results have been obtained in other studies as well (Sansanwal \& Sharma, 1993; Shukla \& Sharma, 1986). When the findings of the present study and the relevant literature have been examined, it has been seen that there is no difference between the genders in general in the context of creativity. However, the reflection of the situation in the real life is different. The rate of representation of women in the fields of physical sciences, technology and mathematics is rather low (Lubinski, Benbow, \& Morelock, 2000). Female students having similar skills and abilities as their male peers keep away from these fields in their course selection and career pursuit. When the results of previous studies (Wang \& Degol, 2013) are taken into consideration, it seems necessary for the female students to be supported in these fields. It can be said that there is a need to develop educational programs that can support the ability domains of women and reveal their potential for scientific creativity especially in the fields such as Physical Sciences, Technology and Mathematics (Kanl1, 2017).

While the individuals engaged in sports were found to have higher extroversion $(p<0.05)$ and lower psychoticism $(p<0.05)$ when the creativity and personality traits of the individuals engaged and not engaged in sports were examined, no difference was determined between the ones engaged in individual sports and the ones engaged in team sports in terms of their creativity and personality traits $(p>0.05)$. The findings of the present study suggest that athletes have higher personal traits of extroversion, and, though the differences are not statistically significant, their neuroticism scores are lower than the average. These findings are also consistent with the results of many previous studies (Rhodes, Couneya, \& Bobick, 2001; Conner \& Abraham, 2001; Naseri, Pakdaman, \& Asgari, 2008; Saklofske, Austin, Rohr, \& Andrews, 2007; Arai \& Hisamichi, 1998; Potgieter \& Venter, 1995; Davis, Elliott, Dionne, \& Mitchell, 1991; Yeung \& Hemsley, 1997). Sports help in increasing more positive emotions such as happiness, liveliness, optimism and activity (David, Green, Martin, \& Slus, 1997; Magnus, Diener, Fujita, \& Pavot, 1993) and in decreasing the negative emotions such as fear, worry, anger and guilt (David et al., 1997; Robinson, Ode, Moeller, \& Goetz, 2007). These necessities are closely related to the personality traits of extroversion and neuroticism (Nia \& Besharat, 2010). While the personality traits of a high level of extroversion and a low level of neuroticism help in preparing the individual for participation in sports activities and contests, the sports activities 
affect the development of these traits as well.

\section{Conclusion}

Consequently, it can be said that the female students are more neurotic, the individuals engaged in sports are more extrovert compared to the ones who are not engaged in sports, and the male students have higher scores in the domains of scholarly creativity, scientific/mechanical creativity, artistic creativity and psychoticism compared to the scores of the female students. The correlation between psychological characteristics and sports and creativity is one of the least investigated subjects in the field of sports psychology. In order to determine the value of the psychological variables involved in the definition of ability, it can be suggested to adopt the studies as longitudinal and semi-longitudinal designs and conduct more specific studies with longer durations.

\section{References}

Ackerman, P. L., Chamorro-Premuzic, T., \& Furnham, A. (2011). Trait complexes and academic achievement: Old and new ways of examining personality in educational contexts. British Journal of Educational Psychology, 81, 27-40. https://doi.org/10.1348/000709910X522564

Ackerman, P., \& Wolman, S. (2007). Determinants and validity of self-estimates of abilities and self-concept $\begin{array}{lllll}\text { measures. } & \text { Journal }\end{array}$ http://psycnet.apa.org/doiLanding?doi=10.1037\%2F1076-898X.13.2.57.

Arai, Y., \& Hisamichi, S. (1998). Self-reported exercise frequency and personality: A population-based study in Japan. Perceptual and Motor Skills, 87(3), 1371-1375. https://doi.org/10.2466/pms.1998.87.3f.1371.

Baer, J., \& Kaufman, J. C. (2008). Gender differences in creativity. Journal of Creative Behavior, 42(2), 75-105. https://doi.org/10.1002/j.2162-6057.2008.tb01289.x

Batey, M., \& Furnham, A. (2006). Creativity, intelligence and personality: A critical review of the scattered literature. Genetic, Social and General Psychology Monographs, 132(4), 355-429. https://doi.org/10.3200/MONO.132.4.355-430.

Batey, M., Furnham, A. F., \& Safiullina, X. (2010). Intelligence, general knowledge and personality as predictors of creativity. Learning and Individual Differences, 20, 532-535. https://doi.org/10.1016/j.lindif.2010.04.008

Cabeza, R., \& Nyberg, L. (2000). Imaging cognition II: An empirical review of 275 PET and fMRI studies. Journal of Cognitive Neuroscience, 12, 1-47. https://doi.org/10.1162/08989290051137585

Chamorro-Premuzic, T., \& Reichenbacher, L. (2008). Effects of personality and threat of evaluation on divergent and convergent thinking. Journal of Research in Personality, 42, 1095-1101. https://doi.org/10.1016/j.jrp.2007.12.007

Chapman, B. P., Duberstein, P. R., Sörensen, S., \& Lyness, J. M. (2007). Gender differences in five factor model personality traits in an elderly cohort: extension of robust and surprising findings to an older generation. Personality and Individual Differences. 43(6), 1594-603. https://doi.org/10.1016/j.paid.2007.04.028

Conner, M., \& Abraham, C. (2001). Conscientiousness and the theory of planned behavior: Toward a more complete model of the antecedents of intentions and behavior. Personality and Socil Psychology Bulletin, 27(11), 1547-1561. https://doi.org/10.1177/01461672012711014

David, J. P., Green, P. J., Martin, R., \& Slus, J. (1997). Differential roles of neuroticism, extraversion, and event desirability for mood in daily life: an integrative model of top-down and bottom-up influence. Journal of Personality and Social Psychology, 73(1), 149-159. http://dx.doi.org/10.1037/0022-3514.73.1.149

Davis, C., Elliott, S., Dionne, M., \& Mitchell, I. (1991). The relationship of personality factors and physical activity to body satisfaction in men. Personality and Individual Differences, 12(7), 689-694. https://doi.org/10.1016/0191-8869(91)90224-Y

Deci, E. L., \& Ryan, R. M. (2000). The 'what' and 'why' of goal pursuits: Human needs and the self-determination of behaviour. Psychological Inquiry, 11(4), 227-268. https://doi.org/10.1207/S15327965PLI1104_01

Dietrich, A. (2004). The cognitive neuroscience of creativity. Psychonomic Bulletin \& Review, 11(6), 1011-1026. https://doi.org/10.3758/BF03196731

Duncan, J., \& Owen, A. M. (2000). Common regions of the human frontal lobe recruited by diverse cognitive 
demands. Trends in Neuroscience, 23, 475-483. https://doi.org/10.1016/S0166-2236(00)01633-7

Eysenck, H. J., \& Eysenck, S. B. (1975). Manual of the Eysenck Personality Questionnaire (adult and junior). Hodder \& Stoughton, London.

Eysenck, S. B. G., Eysenck, H. J., \& Barrett, P. (1985) A revised version of the psychoticism scale. Personality and Individual Differences, 6(1), 21-29. https://doi.org/10.1016/0191-8869(85)90026-1

Feist, G. J. (1998). A meta-analysis of the impact of personality on scientific and artistic creativity. Personality and Social Psychological Review, 2(4), 290-309. https://doi.org/10.1207/s15327957pspr0204_5

Forrest, S., Lewis C. A., \& Shevlin, M. (2000). Examining the factor structure and gender bias of the Eysenck personality Questionnaire Revised-Abbreviated. Personality and Individual Difference, 29(3), 579-588. http://dx.doi.org/10.1016/S0191-8869(99)00220-2

Francis, L. J., Brown, L. B., \& Philipchalk. R. (1992). The development of an abbreviated form of the revised Eysenck Personality Questionnaire (EPQR-A): its use among students in England, Canada, the USA and Australia. Personality and Individual Difference, 13(4), 443-449. https://doi.org/10.1016/0191-8869(92)90073-X

Freund, P. A., \& Kasten, N. (2012). How smart do you think you are? A meta-analysis on the validity of self-estimates of cognitive ability. Psychological Bulletin, 138(2), 296-321. http://dx.doi.org/10.1037/a0026556

Furnham, A. F., Crump, J., Batey, M., \& Chamorro-Premuzic, T. (2009). Personality and ability predictors of the consequences test of divergent thinking in a large non-student sample. Personality and Individual Differences, 46(4), 536-540. https://doi.org/10.1016/j.paid.2008.12.007

Furnham, A., von Stumm, S., Makendrayogam, A., \& Chamorro-Premuzic, T. (2009). The taxonomy of self-estimated human performance. Journal of Individual Differences, 30, 188-193. https://doi.org/10.1027/1614-0001.30.4.188

Haimovitz, K., Wormington, S. V., \& Corpus, J. H. (2011). Dangerous mindsets: How beliefs about intelligence predict motivational change. Learning and Individual Differences, 21(6), 747-752. https://doi.org/10.1016/j.lindif.2011.09.002

Hanin, Y., Eysenck, S. B. G., Eysenck, H. J. \& Barrett, P. (1991). A crosscultural study of personality: Russia and England. Personality and Individual Difference, 12(3), 265-271. https://doi.org/10.1016/0191-8869(91)90112-O

Hughes, D. J., Furnham, A., \& Batey, M. (2013). The structure and personality predictors of self-rated creativity. Thinking Skills and Creativity, 9, 76-84. https://doi.org/10.1016/j.tsc.2012.10.001

Kanl, E. (2017). Investigating the relations between scientific creativity, gender and scientific attitudes of gifted learners. Elementary Education Online, 16(4), 1792-1802. https://doi.org/10.17051/ilkonline.2017.342992

Karanc1, N., Dirik, G., \& Yorulmaz, O. (2007). Reliability and validity studies of Turkish translation of Eysenck Personality Questionnaire Revised-Abbreviated. Turk Psikiyatri Dergisi, 18(3), 254-261.

Kaufman, J. C. (2012). Counting the muses: Development of the Kaufman Domains Of Creativity Scale (K-DOCS). Psychology of Aesthetics, Creativity, and the Arts, 6(4), 298-308. http://dx.doi.org/10.1037/a0029751

Lehmann, R., Denissen, J. J., Allemand, M., \& Penke, L. (2013). Age and gender differences in motivational manifestations of the Big Five from age 16 to 60. Developmental Psychology, 49(2), 365-83. http://dx.doi.org/10.1037/a0028277

Lubinski, D., Benbow, C. P., \& Morelock, J. M. (2000). Gender differences in engineering and the physical sciences among the gifted: An inorganic-organic distinction. In K. A. Heller, F. J. Mönks, R. J. Sternberg \& R. F. Subotnik (Eds.), International handbook of giftedness and talent (2nd Ed.) (pp. 633-648). Elsevier Science Ltd.

Lynn, J., Teno, J. M., Phillips, R. S., Wu, A. W., Desbiens, N., \& Harrold, J. (1997). Perceptions by family members of the dying experience of older and seriously ill patients. Annals of Internal Medicine, 126(2), 97-106. https://doi.org/10.7326/0003-4819-126-2-199701150-00001

Magnus, K., Diener, E., Fujita, F., \& Pavot, W. (1993). Extraversion and neuroticism and predictors of objective life events: a longitudinal analysis. Journal of Personality and Social Psychology, 65(5), 1046-1053. http://dx.doi.org/10.1037/0022-3514.65.5.1046

Maltby, J., \& Talley, M. (1998). The psychometric properties of an abbreviated form of the Revised Junior Eysenck Personality Questionnaire (JEPQR-A) among 12-25-year-old U. S. young persons. Personality and Individual 
Difference, 24(6), 891-893. https://doi.org/10.1016/S0191-8869(97)00234-1

Memmert, D., \& Roth, K. (2007). The effects of non-specific and specific concepts on tactical creativity in team ball sports. Journal of Sports Sciences, 25(12), 1423-1432. https://doi.org/10.1080/02640410601129755

Menglekamp, C., \& Jager, R. (2007). Self-estimates of attention performance. Psychology Science, 49(3), 223-237.

Naseri, T., Pakdaman, Sh., \& Asgari, A. (2008). The role of sport and personality traits in psychological development of students. Journal of Iranian Psychologist, 5, 53-62.

Nia, M. E., \& Besharat, M. A. (2010). Comparison of athletes' personality characteristics in individual and team sports. Procedia-Social and Behavioral Sciences, 5, 808-812. https://doi.org/10.1016/j.sbspro.2010.07.189

Petrides, K. V., Furnham, A., \& Martin, N. (2004). Estimates of emotional and psychometric intelligence: Evidence for gender-based stereotypes. Journal of Social Psychology, 144(2), 149-162. https://doi.org/10.3200/SOCP.144.2.149-162

Potgieter, J. R., \& Venter, R. E. (1995). Relationship between adherence to exercise and scores on extraversion and neuroticism. Perceptual and Motor Skills, 81(2), 520-522. DOI:10.2466/pms.1995.81.2.520.

Putwain, D. W., Kearsley, R., \& Symes, W. (2012). Do creativity self-beliefs predict literacy achievement and motivation? Learning and Individual Differences, 22(3), 370-374. https://doi.org/10.1016/j.lindif.2011.12.001

Rhodes, R. E., Couneya, K. S., \& Bobick, T. M. (2001). Personality and exercise participation across the breast cancer experience. Psycho-Oncology, 10, 380-388. https://doi.org/10.1002/pon.516

Robinson, M. D., Ode, S., Moeller, S. K., \& Goetz, P. W. (2007). Neuroticism and affective priming: Evidence for a neuroticism-linked negativeschema. Personality And Individual Differences, 42(7), 1221-1231. https://doi.org/10.1016/j.paid.2006.09.027

Runco, M. A. (2004). Creativity. Annual Review of Psychology, 55, 657-687. https://doi.org/10.1146/annurev.psych.093008.100416

Saklofske, D. H., Austin, E. J., Rohr, B. A., \& Andrews, J. J. W. (2007). Personality, emotional intelligence and exercise. Journal of Health Psychology, 12(6), 937-948. https://doi.org/10.1177/1359105307082458

Sanchez-Ruiz, M. J., Hernandez-Torrano D., Perez-Gonzalez, J. C., Batey, M. \& Petrides, K. V. (2011). The relationship between trait emotional intelligence and creativity across subject domains. Motivation and Emotion, 35(4), 461-473. https://doi.org/10.1007/s11031-011-9227-8

Sansanwal, D. N., \& Sharma, D. (1993). Scientific creativity as a function of intelligence, self-confidence, sex and standard. Indian Journal of Psychometry and Education, 24(1), 37-44.

Shevlin, M., Bailey, F. \& Adamson, G. (2002). Examining the factor structure and sources of differential functioning of the Eysenck Personality Questionnaire Revised-Abbreviated. Personality and Individual Difference, 32(3), 479-487. https://doi.org/10.1016/S0191-8869(01)00049-6

Shukla, J. P., \& Sharma, V. P. (1986). Sex differences in scientific creativity. Indian Psychological Review, 30(3), 32-35.

Şahin, F. (2016). Adaptation of the Kaufman Domains of Creativity Scale into Turkish and Examination of its Psychometric Properties. Elementary Education Online, 15(3), 855-867. https://doi.org/10.17051/io.2016.70479

Vassend, O., Røysamb, E., \& Nielsen, C. S. (2013). Five-factor personality traits and pain sensitivity: a twin study. Pain 154(5), 722-8. https://doi.org/10.1016/j.pain.2013.01.010

Wang, M. T., \& Degol, J. (2013). Motivational pathways to STEM career choices: Using expectancy-value perspective to understand individual and gender differences in STEM fields. Developmental Review, 33(4), 304-340. https://doi.org/10.1016/j.dr.2013.08.001

Wolfradtz, U., Felfe, J. \& Köster, T. (2002). Self-perceived emotional intelligence and creative personality, Imagination, Cognition and Personality, 21(4), 293-309. https://doi.org/10.2190/B3HK-9HCC-FJBX-X2G8

Yeung, R. R., \& Hemsley, D. R. (1997). Personality, exercise and psychological well-being: static relationships in the community. Personality and Individual Differences, 22(1), 47-53. https://doi.org/10.1016/S0191-8869(96)00158-4 